\title{
Estresse e Lócus de Controle em Adolescentes Grávidas
}

Stress and Locus of Control in Pregnant Teenagers

Estrés y Locus de Control en Adolescentes Embarazadas

Thyara Rúbia Vanderlei de Góes ${ }^{1}$

Divanise Suruagy Correia ${ }^{2}$

\section{Resumo}

Objetivo: Analisar a associação entre o estresse e o lócus de controle. Método: Foram pesquisadas adolescentes grávidas em sete Unidades de Saúde da Família, Maceió, selecionadas por sorteio simples, sendo uma unidade de cada distrito sanitário. Estudo transversal analítico cujos dados foram coletados através de questionário socioeconômico, Escala multifatorial de Lócus de Controle e Inventário de Sintomas de Estresse. Os dados foram analisados no programa Epi Info versão 3.5, usando-se odds como medida estatística. Resultados: Pesquisou-se 39 adolescentes grávidas, de 10 a 19 anos, identificando-se que houve alto índice de estresse, apesar da maior predominância do lócus interno não houve associação estatística significativa entre este e o estresse. Conclusão: Os resultados mostram a necessidade de mais estudos e ações preventivas relacionadas ao tema.

\section{Descritores: Gravidez; Adolescente; Estresse Psicológico.}

\footnotetext{
${ }^{1}$ Assistente Social, Especialista em Saúde Pública pela Universidade Federal de Alagoas. Autora correspondente: Rua Professora Noemia Gama Ramalho, 80. Jacarecica. 57038620. Maceió-Al, Brasil. E-mail:thyaravanderlei@hotmail.com

${ }^{2}$ Professora associada da Faculdade de Medicina da Universidade Federal de Alagoas.

Recebido: 1/3/2016 - Aceito: 10/3/2016.
} 
each health district. Search analytical cross whose data were collected through a questionnaire socioeconomic scale multifactorial, Locus of Control and Stress Symptoms Inventory. Data were analyzed using Epi Info version 3.5, using odds as statistical measure. Results: We surveyed 39 pregnant adolescents, between 10 to 19 years old, identified that there was a high level of stress, despite the predominance of internal locus there wasn't statistically significant association between this and the stress. Conclusion: The results show the need for further studies and preventive actions related to the theme.

\section{Descriptors: Pregnancy; Adolescent;} Stress, psychological.

\section{Resumen}

Objetivo: Con el objetivo de analizar la relación entre el estrés y el locus de control. Método: Fueron encuestadas adolescentes embarazadas, en siete Unidades de Salud Familiar, Maceió, una unidad en cada distrito de salud, seleccionadas por azar simple. Método: Estudio transversal, analítico cuyos datos fueron obtenidos a través de un cuestionario socioeconómico, del locus multifactorial de control y inventario de síntomas de estrés. Los datos fueron analizados en Epi Info versión 3.5, utilizando odds como medida estadística. Resultados: Se encuestó a 39 adolescentes embarazadas, 10-19 años, se identificando que había alto nivel de estrés y que a pesar del predominio del locus interno no hubo asociación estadísticamente significativa entre este y el estrés. Conclusión: Los resultados muestran la necesidad de realizar más estudios y acciones preventivas relacionadas con el tema.

Descriptores: Embarazo; Adolescente; Estrés psicológico.

\section{Introdução}

O desenvolvimento da sexualidade faz parte do crescimento do indivíduo, em direção a sua identidade adulta. Neste contexto, os valores comportamentais dos adolescentes estão mudando bruscamente, principalmente no que diz respeito ao exercício de sua sexualidade, o que acaba acarretando consequências para a vida toda ${ }^{(1)}$.

A ocorrência da gravidez na adolescência é um período importante na vida dos jovens. Isto porque, eles já estão passando por uma fase 
conflituosa, que é a adolescência, momento de saída da infância e começo da vida adulta, ao somar-se uma gravidez inesperada, este momento torna-se duplamente crítico ${ }^{(1)}$.

Por sua vez, o início cada vez mais cedo da vida sexual vem exigindo maior atenção dos profissionais de saúde, devido a suas repercussões, entre elas a gravidez precoce, a qual pode trazer várias consequências para a saúde física e psicológica da adolescente, como é o caso do estresse gestacional. Ter um filho é uma experiência única na vida da mulher e os acontecimentos durante a gravidez, a forma como esse momento especial é vivenciado determina, em grande parte, o bem-estar psicológico e a futura relação com o bebe $^{(2)}$.

Estudos mostram a transformação que um filho provoca $\mathrm{n}$ na vida da mulher, e no caso da adolescente, que ultrapassa momentos importantes do seu desenvolvimento, traz a esta adolescente grávida a situação dela deixar de ser apenas filha, e passar a vivenciar também o papel de mãe $e^{(2)}$.

Qualquer mudança na vida do indivíduo seja ela positiva ou negativa, da qual ele tenha que se adequar rapidamente pode gerar conflito e desequilíbrio, acarretando em situações de estresse. Quando há uma exposição prolongada ao evento estressor este fato torna-se prejudicial à saúde do indivíduo, uma vez que, há predisposição a aparição de determinadas doenças ${ }^{(3)}$.

A resposta do organismo ao estresse é adaptativa, preparando-o para enfrentar o desafio, e a intensidade dessa resposta deve ser proporcional ao agente estressor ${ }^{(4)}$. Assim, o estresse que perdurar por um longo período de tempo pode comprometer o organismo gerando doenças.

A resposta ao estresse é resultante da interação entre as características da pessoa e as demandas do meio. Por sua vez, o lócus de controle é a interpretação que o sujeito faz dos acontecimentos e a percepção que o mesmo tem sobre o controle dos eventos da sua própria vida. É um fator da personalidade definido como a convicção de que as nossas ações influenciam os resultados que obtivemos na vida. O sujeito pode atribuir uma causalidade interna ou externa para os fatos ${ }^{(5)}$.

O lócus de controle é um constructo que tem sido estudado objetivando compreender o processo de aquisição e mudança de comportamento, variável que influencia 
as ações dos indivíduos ${ }^{(5)}$.

Este estudo tem como objetivo analisar a associação entre o estresse e o lócus de controle em adolescentes grávidas, no intuito de contribuir para posteriores estudos sobre o estresse gestacional e um olhar mais atento para essas gestantes.

\section{Método}

Trata-se de um estudo transversal, quantitativo, analítico, realizado com gestantes adolescentes, com idade entre 10 e 19 anos, atendidas nas unidades de saúde da Estratégia de Saúde da Família (ESF), no município de Maceió.

Foram pesquisadas todas as adolescentes das ESF sorteadas, sendo selecionada uma ESF em cada distrito da cidade de Maceió. Como a cidade conta atualmente com 7 distritos sanitários, foram estudadas 7 ESF. No total entrevistou-se 39 gestantes.

Foi aplicado o questionário socioeconômico $^{(6)}$, um questionário de características pessoais $^{(7)}$, o Inventário de Sintomas de Estresse de $\operatorname{Lipp}^{(8)}$ e a Escala Multifatorial de Lócus de Controle $^{(9)}$.

As variáveis estudadas foram: religião, escolaridade, classe social, com quem mora, gravidez planejada, aborto, estresse e lócus de controle.

Anteriormente a coleta de dados, foram capacitados 11 estudantes da área da saúde, para aplicação dos instrumentos de pesquisa. As gestantes foram por eles abordadas nas Unidades de Saúde durante o pré-natal, ou em sua residência, quando da impossibilidade de ser entrevistada na unidade, contando com a ajuda dos agentes comunitários de saúde para localizá-las.

Os Termos de Consentimento Livre e Esclarecido foram lidos e explicados antes da pesquisa e assinados pelas gestantes maiores de 18 anos e por seus responsáveis quando menores de idade.

Os testes ISLL e de lócus de controle foram analisados por psicóloga. Para análise estatística dos dados usou-se o Epi Info versão 3.5 e as medidas de frequência e qui-quadrado.

A pesquisa foi aprovada pelo Comitê de Ética em Pesquisa do Centro de Estudos Superiores de Maceió (CESMAC) protocolo $\mathrm{n}^{\circ} 25000.196371 /$ 2011-70.

\section{Resultados}

Nas setes Unidades de Estratégia de Saúde da Família pesquisadas foram encontradas 39 gestantes adolescentes, cuja média de idade foi de 16 anos, 
sendo a menor idade de 13 anos e a maior 19. Quanto às semanas de gestação, variaram entre a $5^{\circ}$ e a $38^{\circ}$, com a média de 21 semanas.

Tabela 1 - Distribuição das adolescentes por religião, moradia, escolaridade, classe social e presença de estresse.

\begin{tabular}{|c|c|c|c|c|c|c|}
\hline \multirow{3}{*}{ Estresse } & \multicolumn{6}{|c|}{ Religião } \\
\hline & \multicolumn{2}{|c|}{ Católica } & \multicolumn{2}{|c|}{ Evangélica } & \multicolumn{2}{|c|}{ Sem religião } \\
\hline & $\mathrm{n}$ & $\%$ & $\mathrm{n}$ & $\%$ & $\mathrm{n}$ & $\%$ \\
\hline Sim & 15 & 78,9 & 4 & 57,1 & 11 & 8,6 \\
\hline Não & 4 & 21,1 & 3 & 42,9 & 2 & 15,4 \\
\hline \multirow[t]{4}{*}{ Total } & 19 & 100 & 7 & 100 & 13 & 100 \\
\hline & \multicolumn{6}{|c|}{ Com que mora } \\
\hline & \multicolumn{2}{|c|}{ Pais } & \multicolumn{2}{|c|}{ Companheiro } & \multicolumn{2}{|c|}{ Outros } \\
\hline & $\mathrm{n}$ & $\%$ & $\mathrm{n}$ & $\%$ & $\mathrm{n}$ & $\%$ \\
\hline Sim & 14 & 93,3 & 15 & 68,2 & 1 & 50,0 \\
\hline Não & 1 & 6,7 & 7 & 31,8 & 1 & 50,0 \\
\hline Total & 15 & 100 & 22 & 100 & 2 & 100 \\
\hline
\end{tabular}

Escolaridade (nível)

\begin{tabular}{lcccccc} 
& \multicolumn{2}{c}{ Médio } & \multicolumn{2}{c}{ Fundamental } & \multicolumn{2}{c}{ Até a $4^{\circ}$ série } \\
& $\mathrm{n}$ & $\%$ & $\mathrm{n}$ & $\%$ & $\mathrm{n}$ & $\%$ \\
Sim & 3 & 75,0 & 19 & 73,1 & 7 & 87,5 \\
Não & 1 & 25,0 & 73,1 & 26,9 & 1 & 12,5 \\
Total & 4 & 100 & 100 & 100 & 8 & 100
\end{tabular}

Classe Social
C1
$\mathrm{C} 2$
$\mathrm{D}$

$\begin{array}{llllrll} & \mathrm{n} & \% & \mathrm{n} & \% & \mathrm{n} & \% \\ \text { Sim } & 3 & 50,0 & 18 & 75,0 & 9 & 100 \\ \text { Não } & 3 & 50,0 & 6 & 25,0 & 0 & 0 \\ \text { Total } & 6 & 100 & 24 & 100 & 9 & 100\end{array}$


Do total, $48,7 \%$ das gestantes afirmaram ser católicas, 17,9\% evangélicas e 33,3\% disseram não ter religião. A maioria mora com o companheiro $(56,4 \%)$ e $38,5 \%$ mora com os pais.

Com relação à escolaridade, $68,4 \%$ tem o fundamental completo, apenas $10,5 \%$ tem o nível médio completo. Observou-se que $61,5 \%$ pertencem a classe $\mathrm{C} 2$, e de acordo com $\mathrm{ABEP}^{(6)}, \quad 21,8 \%$ dos brasileiros pertencem a essa classe.

Verificou-se que $93,3 \%$ das adolescentes que moravam com os pais tinham algum nível de estresse, entre as que moravam com o companheiro a frequência de estresse foi de 68,2\% (tabela1).

Pode-se constatar ainda que em relação à classe social, quanto mais baixo a classe social maior a porcentagem de adolescentes com estresse, o que mostra que o fator econômico também contribuiu para o aparecimento do estresse, uma vez que elas se mostravam preocupadas em como sustentaria a nova família que formou, no momento da coleta dos dados.

Tabela 2- Distribuição das adolescentes quanto à gravidez e aborto e presença de estresse.

\begin{tabular}{|c|c|c|c|c|}
\hline \multicolumn{5}{|c|}{ Gravidez Planejada } \\
\hline \multirow[t]{2}{*}{ Estresse } & \multicolumn{2}{|c|}{ Sim } & \multicolumn{2}{|c|}{ Não } \\
\hline & $\mathrm{n}$ & $\%$ & $\mathrm{n}$ & $\%$ \\
\hline Sim & 5 & 71,4 & 25 & 78,1 \\
\hline Não & 2 & 28,6 & 7 & 21,9 \\
\hline \multirow[t]{4}{*}{ Total } & 7 & 100 & 32 & 100 \\
\hline & \multicolumn{4}{|c|}{ Aborto } \\
\hline & \multicolumn{2}{|c|}{ Sim } & \multicolumn{2}{|c|}{ Não } \\
\hline & $\mathrm{n}$ & $\%$ & $\mathrm{n}$ & $\%$ \\
\hline Sim & 4 & 100 & 26 & 74,3 \\
\hline Não & 0 & 0,0 & 9 & 25,7 \\
\hline Total & 4 & 100 & 35 & 100 \\
\hline
\end{tabular}

Quando perguntado se a gravidez foi planejada, $82,1 \%$ afirmou que não, e
15,4\% já havia tido um filho. Apesar de planejar a gravidez, algumas delas 
apresentavam estresse (71,4\%). As adolescentes também foram questionadas quanto ao aborto, das 39 entrevistadas, $4(10,3 \%)$ afirmaram já ter sofrido ou provocado um aborto e todas elas apresentavam algum nível de estresse (Tabela 2).

O maior índice de estresse está nas adolescentes que disseram ser a gravidez não planejada. Dessas meninas, $78,1 \%$ apresentam algum nível de estresse (Tabela 2).
Foi observado que das 39 gestantes entrevistadas, apenas $28,2 \%$ não apresentavam sinais de estresse, enquanto $71,9 \%$ têm algum nível de estresse, sendo que, $51,3 \%$ estão na fase de resistência, e 18,7\% na fase de quase exaustão. Apesar de fazer parte do Inventário de Sinais e Sintomas de Lipp, dentre as adolescentes pesquisadas, não foi identificada nenhuma na fase de exaustão (gráfico 1).

\section{Gráfico 1- Distribuição das adolescentes pesquisadas quanto ao estresse e}

\section{fases de estresse}

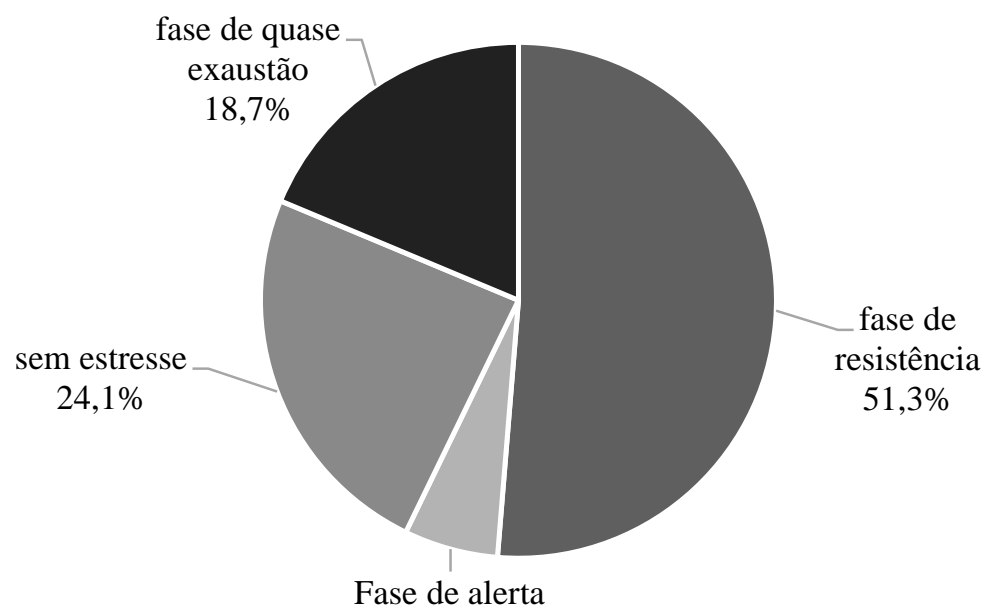

Fase de alerta

- resitência $\quad$ alerta $\stackrel{5,9 \%}{\square}$ sem estresse - quase exaustão
Quanto ao lócus de controle, 48,7\% das gestantes apresenta lócus interno (autoconfiantes) e 12,8\% são concretos, $5,1 \%$ crentes, $\quad 17,9 \%$ incrédulos, $5,1 \%$ inseguros, $5,1 \%$ insubmissos, e 5,1\% místicos. Os resultados foram corrigidos de acordo com as instruções de correlação da escala de lócus de controle, uma vez que, em alguns casos é impossível classificar o sujeito apenas como interno ou externo (Tabela 3). 
Tabela 3 - Distribuição das adolescentes quanto ao estresse e lócus de controle.

\begin{tabular}{cllll}
\hline Estresse & \multicolumn{2}{c}{ Lócus interno } & \multicolumn{2}{c}{ Lócus externo } \\
& $\mathrm{n}$ & $\%$ & $\mathrm{n}$ & $\%$ \\
Sim & 14 & 73,7 & 16 & 80 \\
Não & 5 & 26,3 & 4 & 20 \\
Total & 19 & 100 & 20 & 100 \\
\hline Valor de $\mathrm{p}=0,33162$ & odds ratio & $=$ de $1,4155 .\left(\mathrm{IC}_{95 \%}=0,3004-7,0188\right)$.
\end{tabular}

Apesar da frequência de estresse ter sido maior nas adolescentes classificadas com lócus interno (tabela 3), não se encontrou significância estatística nos resultados deste estudo, talvez pelo tamanho da amostra. Este resultado mostra a necessidade de um estudo maior, com aprofundamento da análise.

\section{Discussão}

A literatura a respeito do estresse na gestação é escassa, e associada ao lócus de controle é inexistente, o que dificulta comparações e uma análise mais detalhada a respeito de seus indicadores.

A adolescência, a gravidez e o climatério são os três períodos críticos do ciclo vital da mulher, uma vez que, constituem fases do desenvolvimento da personalidade. Nesses períodos as mulheres ficam mais propensas a mudanças no seu estado de humor e a alterações em sua identidade ${ }^{(1)}$.

De acordo com Arrais \&; Azevedo $^{(1)}$ por maiores que tenham sido as conquistas históricas do movimento feminista, em nossa sociedade ainda predomina a cultura machista, onde cabe à mulher, praticamente toda a criação e educação do filho, esperam-se um modelo de mãe perfeita, compreensiva, equilibrada, amável. Dessa forma, há um conflito entre o ideal e o vivido, o que causa um sofrimento psíquico e pode ser a base para uma depressão pós-parto.

A vocação materna é construída, pois é impossível saber como lidar com uma situação sem tê-la vivido anteriormente. O modelo ideal de mãe, associado a uma gravidez precoce, onde na maioria dos casos, a jovem ainda não tem condições financeiras e nem 
psicológicas para cuidar de uma criança a leva a um estado de ansiedade e preocupação.

Segundo a $\mathrm{OMS}^{(10)}$ anualmente 16 milhões de adolescentes, entre 15 e 19 anos dão à luz a um bebê, e uma a cada cinco meninas engravidam até os 18 anos de idade no mundo. Cerca de três milhões de adolescentes entre 15 e 19 anos fazem abortos inseguros todos os anos. Complicações na gravidez e no parto são a primeira causa de morte entre meninas de 15 a 19 anos em países pobres.

Estudos revelam $^{(11-12)}$ que a baixa renda e a pouca escolaridade contribuem muito para a gravidez precoce, pois muitas adolescentes não sabem como evitar um filho ou não têm acesso aos métodos contraceptivos, o que faz com que essas jovens se sujeitem a abortos ilegais. Como podemos observar (tabela I) quanto menor o nível econômico maior o aparecimento de estresse, $100 \%$ das adolescentes que pertencem à classe $\mathrm{D}$ têm algum nível de estresse, a preocupação em como sustentar a nova família, ou ter que depender de outras pessoas para se alimentar e comprar as coisas para o enxoval de seu filho pode ser um dos motivos.
Embora muitas vezes a adolescente já tenha parado de estudar antes de engravidar, é comum que o abandono escolar aconteça durante a gravidez, o que leva a condições que dificultam a superação da pobreza, uma vez que tem que se submeter a trabalhos informais e mal remunerados. Das adolescentes pesquisadas, apenas 10,5\% têm o nível médio completo, $68,4 \%$ têm apenas o nível fundamental, nenhuma tem nível superior.

Quando a gravidez não é planejada e a gestante não tem o apoio do pai da criança e/ou familiar é ainda mais complicado. Isto pode gerar baixa autoestima e estresse, o que acaba influenciando na relação da gestante com o seu bebê, transformando-se em um momento estressante quando a mãe se sente angustiada, insegura, sensível $^{(12)}$. Como também nos mostra um estudo(7), o qual afirma que na gravidez não planejada pode haver aumento de repercussões emocionais negativas, entre elas a baixa autoestima, sintomas depressivos e aumento de estresse, o que reafirma os dados da amostra, onde $82,1 \%$ das adolescentes afirmam não terem planejado a gravidez e $76,9 \%$ das adolescentes pesquisadas apresentaram algum nível de estresse. 
$\mathrm{Na}$ amostra aqui estudada, 93,3\% das gestantes que moram com os pais apresentaram estresse (tabela 1). As suposições são várias, para um índice tão alto, como por exemplo, um possível abandono do pai da criança, o que gera uma maior responsabilidade da mãe em criar sozinha a criança, uma cobrança maior dos pais ou conflitos pelo fato de engravidar, são fatores que podem provocar o surgimento do estresse.

De acordo com a Síndrome Geral da Adaptação (SGA) o estresse é classificado em três fases, alerta, resistência e exaustão. Uma, pesquisadora brasileira, destacou outra fase em seus estudos, a fase da quase exaustão $^{(10)}$. No presente estudo $10,3 \%$ das adolescentes pesquisadas estavam na fase de alerta (gráfico 1), momento em que o sujeito é colocado em prontidão para encarar os desafios, é o despertar do sujeito em direção ao enfrentamento da situação, é assim, considerada uma fase positiva. Surgem sintomas como palidez, suor frio nas mãos e nos pés, lentidão da digestão, entre outros.

Contudo, mais da metade, ou seja, $51,3 \%$ já estão na fase de resistência (gráfico 1), onde, segundo a literatura os principais sintomas são: ansiedade, medo, impotência sexual, isolamento social $^{(7)}$.

Esses sintomas aparecem no estresse, quando o fenômeno é de longa duração. De acordo com Lipp ${ }^{(13)}$ nessa fase, o organismo provoca alterações fisiológicas, fazendo com que as alterações que são comuns ao processo de gestação fiquem ainda mais exacerbadas, o que causa o surgimento de patologias não comuns em uma gravidez normal.

Foi encontrado que $10,3 \%$ das gestantes estão na fase de quase exaustão, fase na qual há a persistência dos fatores estressantes ocasionando a queda da resistência do organismo e o consequente adoecimento. Se o estresse ainda persistir, o organismo já está esgotado e busca reequilibrar-se, afetando, dessa forma, outras funções vitais, e é quando aparecem as doenças mais graves.

Fato este que indica a urgente necessidade de pesquisas nesta área para melhor compreensão de seus indicadores, bem como para a futura construção de possíveis ações que possam ajudar a diminuir o estresse em adolescentes grávidas. O que é corroborado quando se compara estes dados com o estudo de Correia $^{(7)}$ onde foram pesquisadas adolescentes 
grávidas nas unidades de saúde em Maceió, que obteve também um alto índice de jovens que apresentavam sintomas de estresse $(80,7 \%)$, e entre essas, $57,1 \%$ também estavam na fase de resistência e 18,6\% na fase de exaustão.

$\mathrm{O}$ alto índice de estresse nessas adolescentes, segundo a literatura, pode ser explicado pelo fato de a adolescência já ser uma fase complexa, a qual se caracteriza por alterações físicas e emocionais, e fica ainda mais complicado quando esse momento vem acompanhado de um fato inesperado, como a gravidez ${ }^{(7-14)}$. Além disso, por se sentir envergonhada, insegura, a jovem, muitas vezes se isola do meio social, dos amigos, há atritos familiares, incertezas quanto ao futuro, e alto índice de abandono escolar.

A gravidez na adolescência faz parte de um processo sociocultural, e não é apenas o desenvolvimento da sexualidade, havendo várias causas para que ela ocorra nesse período. Quando a adolescente fica grávida ela pode comprometer etapas do seu desenvolvimento e a transição da infância para a idade adulta ocorre de forma abrupta ${ }^{(1)}$.

Alguns estudos sobre felicidade vêm demonstrando que o controle sobre a sua própria vida está diretamente relacionado com a satisfação que se têm com a mesma ${ }^{(15)}$.

O lócus de controle externo é representado por sujeitos que atribuem a fatores externos, como a sorte, a divindades, o acaso os resultados dos eventos da sua vida, sejam eles negativos ou positivos. As pessoas com lócus de controle externo são mais suscetíveis a serem manipuladas, influenciadas $^{(5)}$.

Por sua vez, o lócus de controle interno é quando o indivíduo acredita que têm controle sobre o que lhes acontece, é a parte em nós que nos permite acreditar que somos os autores da nossa própria história, os sujeitos estão menos propensos a influências e coerções e tendem a se responsabilizar mais pelos seus atos, tomar mais decisões e ter mais iniciativa do que os sujeitos com lócus externo ${ }^{(15)}$. $\mathrm{Na}$ amostra aqui estudada, $48,7 \%$ das adolescentes tem lócus interno, (tabela IV) os outros $51,1 \%$, pertencem ao lócus externo e interno/externo.

Dessa forma, pesquisou-se a relação entre o estresse e o lócus de controle, supondo-se ser o estresse mais presente nas adolescentes com lócus interno, por se responsabilizar mais por suas ações, trazendo a culpa para si. 
Apesar da frequência de estresse ter sido maior no lócus interno (tabela 3), não houve significância estatística, a análise dessa variável no presente estudo, não houve correlação estatística, talvez pelo tamanho da amostra, que foi pequena. Isto mostra a necessidade de outro estudo para validar a hipótese.

\section{Conclusão}

$\mathrm{O}$ alto índice de estresse entre as adolescentes grávidas aqui pesquisadas, principalmente na fase de resistência, mostra a necessidade de um olhar mais atento para o estresse em gestantes, bem como a importância de um serviço de saúde pública, que seja integral, desenvolvendo ações de apoio a essas adolescentes grávidas.

Sugere também a necessidade de outros estudos com um maior número de gestantes para aprofundar o tema e comprovar ou não a hipótese de o estresse ser mais presente nas pessoas com lócus de controle interno.

A ESF deve ser uma ponte para alcançar a universalidade do acesso, a integralidade das ações vigentes, como a equidade, a descentralização, a hierarquização dos serviços e o controle social, dando apoio biopsicossocial a adolescente, ser uma rede de apoio, colaborando para a diminuição do estresse gestacional, através de um prénatal de qualidade e da ação multidisciplinar, que envolva também a família da gestante.

\section{Referências}

1 Arrais AR, Azevedo KR. O mito da mãe exclusiva e seu impacto na depressão pós-parto. Psicol Reflex Crít[internet].2006; [Citado 12 mai. 2012] 269-76. Disponível em: <http://www.scielo.br/scielo.php?script $=$ sci_arttext\&pid=S0102- 79722006000 $200013 \& \operatorname{lng}=\mathrm{pt} \& \mathrm{nrm}=\mathrm{iso} \& \mathrm{t} \operatorname{lng}=\mathrm{pt}>$.

2 Rodrigues OMPR, Schiavo RA. Stress na gestação e no puerpério: uma correlação com a depressão pós-parto. Rev. Bras Ginecol Obstet[internet]. 2011 [Citado 20 mai. 2012]: 252-7. Disponível em: <http://www.scielo.br /scielo.php?pid=S0100-7203201100090 0006\&script $=$ sci_arttext $>$.

3 Rosseti, MO, Ehlers DM, Guntert, IB, Leme IFAS, Rabelo IS, Tosi SMVD, et al. O inventário de sintomas de stress para adultos de lipp (ISSL) em servidores da polícia federal de São Paulo. Rev. bras. ter. cogn. 2008;4(2):108-20.

4 Zuardi, AW. Fisiologia do estresse e sua influência na saúde. São Paulo: USP, Departamento de Neurociência e ciência do comportamento[internet]. 2010 [Citado 12 mai.2012]. Disponível em: <http://rnp.fmrp.usp.br/ psicmed/d oc/Fisiologia\%20do\%20estresse.pdf >.

5 Braga LP. Lócus de Controle e conceito de maternidade e paternidade em adolescentes. [dissertação]. Rio Grande do Norte: Mestrado em 
psicologia, Universidade Federal do Rio Grande do Norte; 2012.

6 Associação Brasileira de Empresas de Pesquisa [internet]. Critério de classificação econômica Brasil. [Citado 18 jun 2012]. Disponível em: $>$ http://www.abep.org/novo/Content.asp $\mathrm{x}$ ?ContentID=301>.

7 Correia DS, Santos LVA, Calheiros AMN, Vieira MJ. Adolescentes grávidas: sinais, sintomas, intercorrências e presença de estresse. Rev Gaúch Enferm [periódico na internet] Porto Alegre, 2011;40-7. [Citado 25 jun. 2012]. Disponível em: <http://www.scielo.br/pdf/rgenf/v32n1/ a05v32n1.pdf $>$.

8 Lipp M. Manual do inventário de sintomas de stress para adultos de Lipp (ISSL). São Paulo: Casa do Psicólogo; 2000.

9 Tamayo Á. Validade fatorial da escala Levenson de Lócus de Controle. Psicol Teor e Pesqui, 1989;5 (1): 111-22.

10 Ministério da Saúde (BR). DATASUS, Brasília (DF); 2012. [Citado 22 abr. 2012]. Disponível em: >http://www.datasus.gov.br/> .

11 Caputo VG, Bordin IA. Gravidez na adolescência e o uso frequente de álcool e drogas no contexto familiar. Rev Saúde Pública[internet]2008. [Citado 10 abr. 2012]: 252-7 Disponível em: $<$ http://www.scielo.br/pdf/rsp/v42n3/61 58.pdf $>$.

12 Baseggio, DB. Fatores correlacionados à gestação de risco e parto prematuro em adolescentes. Rev de Psicol IMED[internet] 2011. [Citado 11 mai. 2012]; 3(1): 506-16. Disponível em: <http://seer.imed.edu.br/index.php /revistapsico/article/view/84>.
13 Lipp M. Escala de stress infantil (ESI). São Paulo: Casa do Psicólogo; 2005.

14 Lima FV. Correlação entre variáveis preditoras de estresse e o nível de estresse. [dissertação]. Brasília (DF): Pós-graduação em educação física, Universidade Católica de Brasília; 2005.

15 Baptista MN, Alves GAS, S0 TMM. Suporte Familiar, Auto-Eficácia e Lócus de controle Evidências de Validade entre os construtos. Psicol Ciênc Prof [periódico na internet] 2008. [Citado 23 mai. 2012]: 260-71. Disponível em: >http://pepsic.bvsalud. org/pdf/pcp/v28n2/v28n2a04.pdf>. 